\title{
Mechanical Behavior and Damage Evolution for Granite Subjected to Cyclic Loading
}

\author{
Zhiliang Wang $\mathbb{D},{ }^{1}$ Jikang Yao, ${ }^{1}$ Nuocheng Tian, ${ }^{2}$ Jingbin Zheng, ${ }^{3}$ and Peng Gao $\mathbb{D}^{1}$ \\ ${ }^{1}$ College of Civil and Hydraulic Engineering, Hefei University of Technology, Hefei 230009, China \\ ${ }^{2}$ College of Resource and Environmental Engineering, Hefei University of Technology, Hefei 230009, China \\ ${ }^{3}$ College of Environmental Science and Engineering, Ocean University of China, Qingdao 266100, China
}

Correspondence should be addressed to Zhiliang Wang; cvewzL@hfut.edu.cn

Received 3 December 2017; Revised 25 January 2018; Accepted 2 April 2018; Published 13 May 2018

Academic Editor: Hongchao Kou

Copyright ( $) 2018$ Zhiliang Wang et al. This is an open access article distributed under the Creative Commons Attribution License, which permits unrestricted use, distribution, and reproduction in any medium, provided the original work is properly cited.

This paper focuses on the mechanical behavior and damage evolution of Huashan granite subjected to cyclic loading. Four levels of confining pressure $(0,15,25$, and $35 \mathrm{MPa})$ were applied during cyclic axial loading by using a Rock Test System (MTS815) along with an acoustic emission (AE) monitoring device. Experimental results indicate that the number of AE activities is higher under cyclic triaxial loading compared to that under cyclic uniaxial loading. The measured stress-strain curves of both uniaxial and triaxial tests under cyclic loading are concave-up, but the degree of concavity is mild for the latter. As the cycle number rises, elastic modulus of the granite sample under different confining pressures increases. The slope of the peak strength versus confining pressure plot for the cyclic loading is larger than that for the monotonic loading. Besides, it is found that the dissipated energy increases with the increase of cyclic stress, but it hardly increases in proportion with the confining pressure. The damage parameters defined in terms of the plastic strain can be extended for the whole cyclic loading process, and they agree well with the energy-based damage parameters.

\section{Introduction}

In geotechnical engineering practices such as tunnel excavation and support, shale gas mining, and safe disposal of nuclear waste, rock material is subjected to different loading conditions (including triaxial versus uniaxial or cyclic versus monotonic). For example, under the cyclic loading, the damage accumulation occurs, and the strength and deformation of rock are closely related with its stress state and loading history [1]. Therefore, it is of importance to explore the effect of loading condition on the damage mechanical behavior of rock.

In the past decades, many scholars have carried out research into the mechanical and damage behaviors of rock subjected to different loading conditions. Xie et al. [2] explored the mechanical properties of fractured marbles under monotonic uniaxial loading and pointed out that failure characteristics of fractured rocks were appreciably controlled by fracture distribution or fracture patterns. Song et al. [3] experimentally investigated the deformation and damage behavior of rock under cyclic uniaxial compression and indicated that when the amplitude of the cyclic loading exceeded a certain value, the applied stress had a significant effect on the strain localization and damage evolution. Liu et al. [4] proposed a damage evolution equation for rock salt under cyclic loading in uniaxial test and reported that, with increasing stress level, the damage evolution became more evident, and a maximum damage of about 0.95 was recorded when the stress level went beyond $85 \%$ of the uniaxial strength. Chen et al. [5] studied the prefailure damage characteristics of rock under monotonic triaxial compression and concluded that the damage increased slowly before the reversal of volumetric strain and accelerated quickly afterwards. Zong et al. [6] explored the mechanical and damage properties of sandstone using monotonic triaxial compression tests. It was found that the strength and deformation increased linearly with confining pressure, and the failure modes transformed from brittleness to ductility as 
the confining pressure increased. Wang et al. [7] investigated the hydromechanical behavior of granite subjected to cyclic loading under triaxial compression conditions and revealed that the stress corresponding to the transition from volumetric compaction to volumetric dilation might be taken as the threshold for fatigue failure. To date, few experimental studies are available for granite under cyclic triaxial loading, especially with the close monitoring of acoustic emission (AE) events.

Recently, there has been an increased interest in $\mathrm{AE}$ study of rock. Based on uniaxial and triaxial compression tests, Zhao et al. [8] discovered that the complete evolution of crack damage during rock deformation could be characterized using the real-time spatial AE locations in combination with the stress-strain relationships. Li et al. [9] experimentally studied the $\mathrm{AE}$ activities of different types of rocks and concluded that the 3-D location of $\mathrm{AE}$ events directly reflected the process of initiation, propagation, and evolution of microcracks and the stress redistribution in the samples. The true triaxial unloading test on limestone was performed by $\mathrm{He}$ et al. [10], studying the $\mathrm{AE}$ accumulated energy release from the unloading state of the rock sample to its failure. Aker et al. [11] associated AEs with the shear and tensile failures around a horizontal borehole in the sandstone sample subjected to triaxial stress. It was found that the AEs followed existing damage models fairly well, but the elastic solution of the hoop stress could not represent the onset of failure around the borehole.

The concept of damage was proposed to describe the extent of the development of flaws such as microcracks and microvoids in a continuum [12]. So far, the damage for rocklike materials has been defined by using many parameters, such as elastic modulus, velocity of elastic wave, and so on. Shao and Khazraei [13] demonstrated that laboratory stressstrain data could be used to establish the required damage parameters and to calibrate the derived damage models. To further investigate the role of cyclic loading in contributing to rock damage, Eberhardt et al. [14] defined damage parameters in terms of the permanent axial, lateral, and volumetric strains. However, description of the damage process using only conventional stress and strain measurements is not sufficient. Since the deformation and failure of rock is an irreversible process of energy dissipation, it is a new trend to study the damage mechanical properties of rock from the viewpoint of energy. Considering the dissipated energy from external forces produced damage and irreversible deformation within rock, Xie et al. [15] proposed the structural failure criteria for rock materials. Liu et al. [16] developed a new damage constitutive model based on energy dissipation, which was able to capture the behaviors of rock under cyclic loading. According to the AE energy, Khazaei et al. [17] quantified the rock damage by defining a related parameter of the total crack surface.

Cyclic compressive tests were performed on granite samples in this study, in order to provide references for evaluating the stability of geological rock masses and give some advice for engineering design, construction, and operation. The main objective is to present the AE characteristics and mechanical behaviors of the granite sample under cyclic loading and unloading. Specifically, key issues such as the energy dissipation, the evolution of microcracks, and the damage definition of the granite rock are discussed. The remainder of the paper is organized as follows: (i) the $\mathrm{AE}$ activities are compared between the samples under cyclic uniaxial and cyclic triaxial loading; (ii) the effect of confining pressure on the cyclic mechanical behaviors of the samples is analyzed; (iii) the characteristics of energy dissipation of the samples under cyclic loading are explored; and (iv) the damage of the samples subjected to cyclic loading under triaxial compressive conditions is evaluated from the perspectives of energy dissipation and plastic strain, respectively, based on which damage parameters are defined and discussed.

\section{Equipment and Test Scheme}

2.1. Raw Material and Sample Preparation. The tested granite was taken from a quarry in the Huashan area (Shanxi Province, northwest China). Huashan granite is greyishwhite, and it has a massive structure, classified as mediumfine-grained biotite granite (particle size: $0.7 \sim 4.0 \mathrm{~mm}$ ). The density of the granite is $2620 \mathrm{~kg} / \mathrm{m}^{3}$, and the main components include microcline $(41 \%)$, plagioclase $(27 \%)$, quartz (22\%), and biotite (7\%), among others. The rock samples were shaped into the cylinders of $\Phi 50 \times 100 \mathrm{~mm}$ in the laboratory, and ISRM standards [18] were followed when cutting the rock core into the cylinder. The depth of parallelism of the upper and lower faces of the cylinder was controlled within $\pm 0.05 \mathrm{~mm}$.

2.2. Experimental Principle. The compressive tests were performed with a rock test system (MTS815), which has the maximum axial load and confining pressure of $1800 \mathrm{kN}$ and $45 \mathrm{MPa}$, respectively. The monotonic compressive tests were firstly conducted to obtain the strengths of granite under different confining pressures. For the loading-unloading tests, five cycles were preset before the sample failed. In fact, the loading and unloading were manually controlled according to the stress level during the tests. The lower limit of cyclic stress during unloading was selected as $0.5 \mathrm{MPa}$ for all five cycles, while the upper limits of the cyclic stress were set in sequence as $15 \%, 30 \%, 45 \%, 60 \%$, and $75 \%$ of the uniaxial/triaxial strength of the sample. Thus, it was demonstrated that the upper limit of cycle was increased from one cycle to the next. Both the axial loading and unloading were applied to the samples at a constant rate of $0.5 \mathrm{MPa} / \mathrm{s}$, while the rate for exerting the confining pressure was $0.2 \mathrm{MPa} / \mathrm{s}$ [18]. During the tests, 4-5 samples were prepared for each loading case to ensure at least three sets of effective data. The ends of the samples were smeared with lubricant to reduce the surface friction.

The measurement of the axial strain was accomplished using an axial extensometer, and lateral deformation was measured by a chain circumferential extensometer. The digital PCI-2 AE system with multiple channels was adopted. In order to achieve a high signal/noise ratio in the uniaxial and triaxial tests, the gains of signal acquisition were set as 




(a)

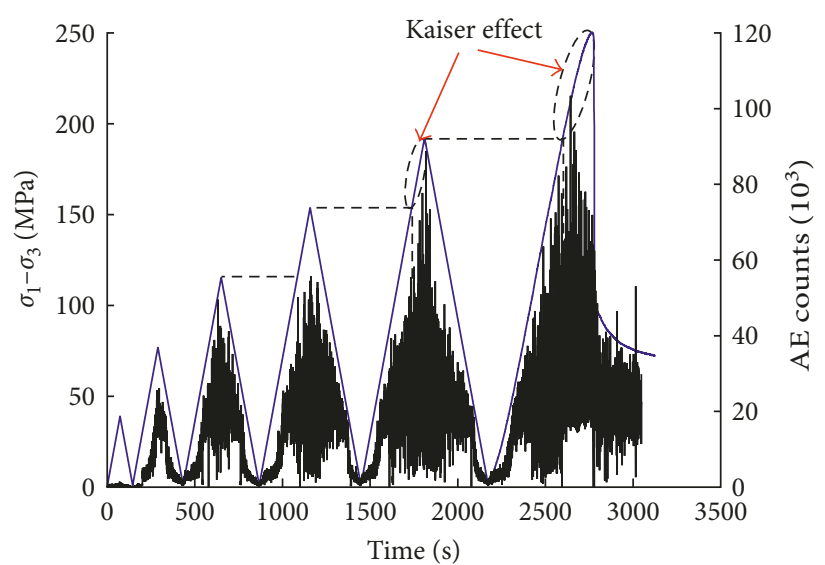

(b)

Figure 1: Time history curves of stress and AE counts of samples under cyclic loading. (a) $\sigma_{3}=0 \mathrm{MPa}$. (b) $\sigma_{3}=35 \mathrm{MPa}$.

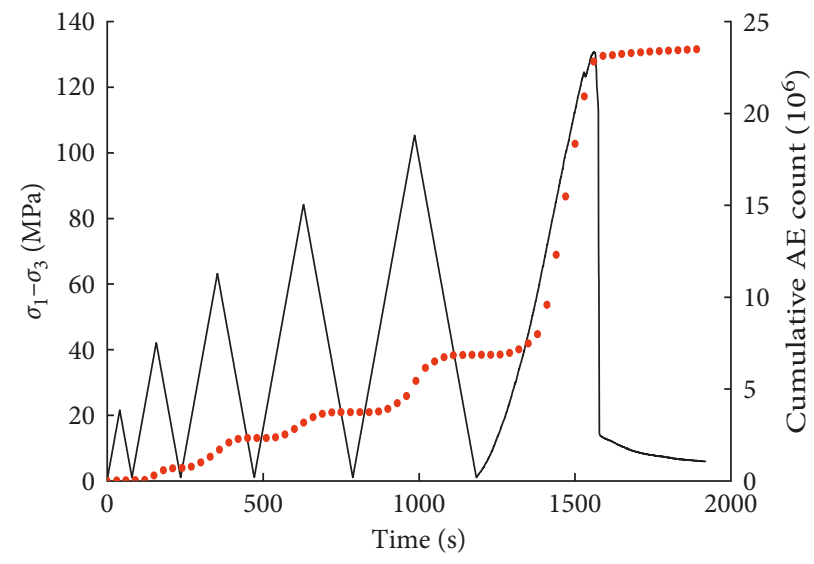

(a)

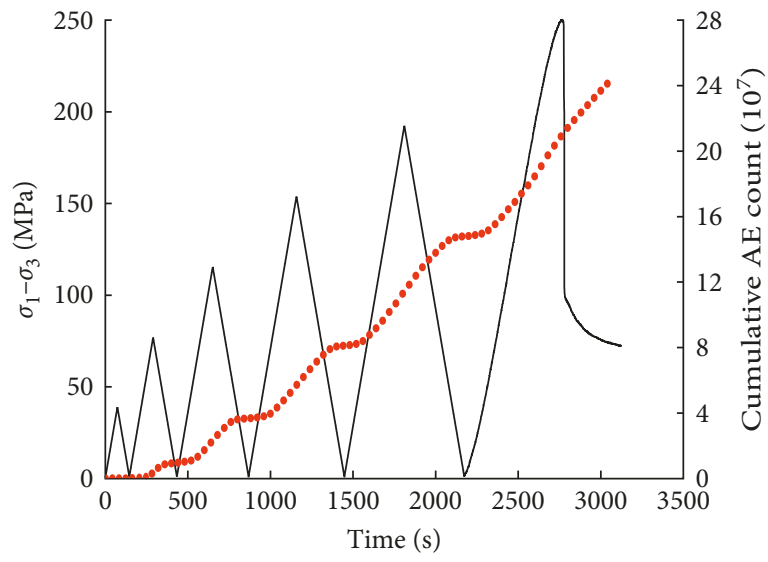

(b)

FIgure 2: Time history curves of stress and cumulative AE count of samples under cyclic loading. (a) $\sigma_{3}=0 \mathrm{MPa}$. (b) $\sigma_{3}=35 \mathrm{MPa}$.

$30 \mathrm{~dB}$ and $36 \mathrm{~dB}$, respectively. Four piezoelectric ceramic probes were used during the testing, by which the AE signals could be easily measured. In the uniaxial test, the AE probes were symmetrically attached to the middle of the sample, while the AE probes were attached to the inner wall of the confining pressure chamber in the triaxial test. It is because the sample was wrapped by a heat shrinkable plastic cover and the probes were unable to directly contact the sample. After the experiments, the number and energy of $\mathrm{AE}$ activities of the samples were analyzed based on the stress-time and stress-strain curves.

\section{Experimental Results}

3.1. Characteristics of Acoustic Emission. The time history curves of stress and AE counts of samples under cyclic loading are shown in Figure 1. It is clear that the AE counts increase with the increase of cyclic stress, implying that the influence of applied load on the AE activities is significant. The highest AE count is observed as the axial stress reaches the peak strength of the sample. Regardless of confining pressure, the AE activities are quiet during the first cycle, and they are still detectable until the sample fails. Besides, once the current stress reaches the peak of the last loading cycle, a dramatic increase in AE activities can be observed. This is known as the Kaiser effect, which illustrates the ability of rock to keep and reproduce the information of stress experienced in the past.

The plots of stress and cumulative AE count versus time under cyclic loading are presented in Figure 2. For the cyclic triaxial loading, the curve of cumulative $\mathrm{AE}$ count is almost linear, while the corresponding curve for the uniaxial case is step-like. Especially during the last cycle of the uniaxial loading, the curve increases sharply and then levels off. In addition, it is noticed that the number of $\mathrm{AE}$ activities under the cyclic triaxial loading is about one order of magnitude greater than that under the cyclic uniaxial case, which indicates that the confining pressure has a significant influence on the AE activities.

\subsection{Characteristic of Mechanical Behavior}

3.2.1. Stress-Strain Curves and Failure Modes. The cyclic stress-strain responses of the samples at $\sigma_{3}=0$ and $35 \mathrm{MPa}$ 




(a)

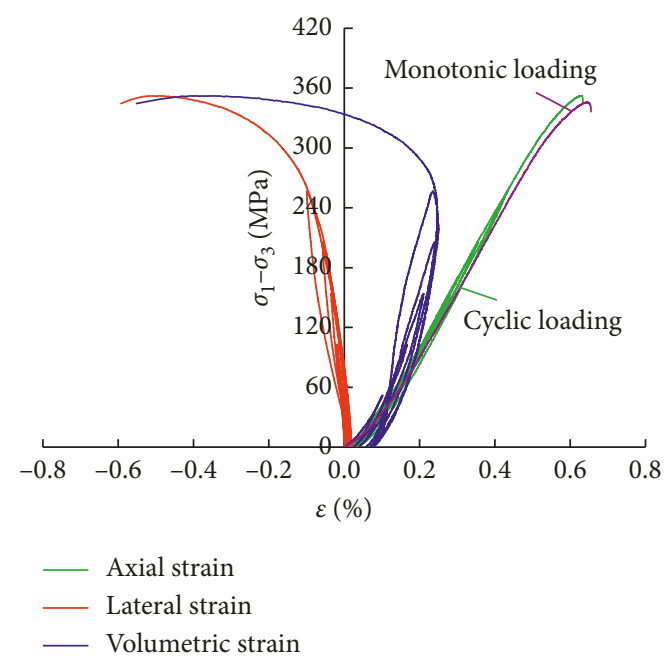

(b)

Figure 3: Stress-strain curves of samples under monotonic and cyclic loading. (a) $\sigma_{3}=0 \mathrm{MPa}$. (b) $\sigma_{3}=35 \mathrm{MPa}$.

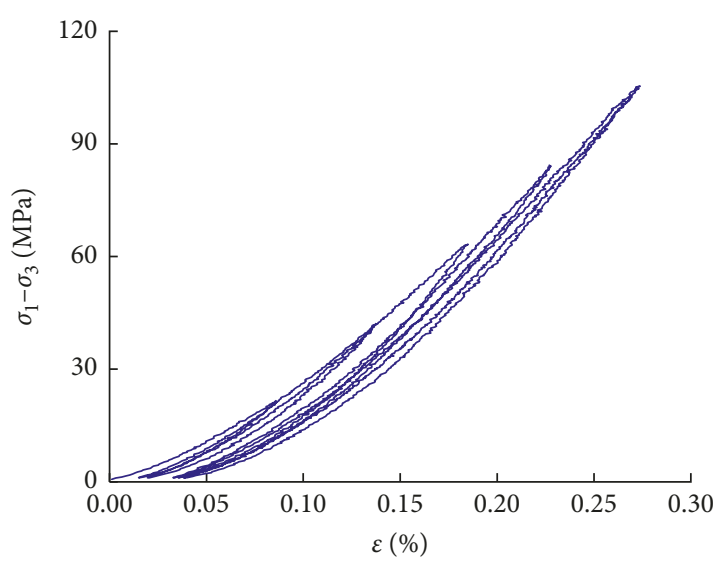

(a)

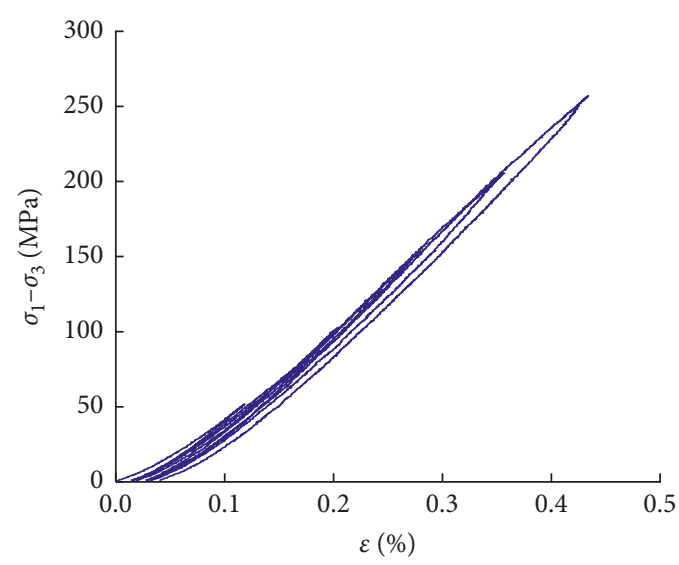

(b)

Figure 4: Comparisons of stress-strain curves during the first five cycles. (a) $\sigma_{3}=0 \mathrm{MPa}$. (b) $\sigma_{3}=35 \mathrm{MPa}$.

are shown in Figure 3. There is no obvious difference between the shapes of stress-strain curves under cyclic uniaxial and triaxial loading, except that the peak strength for the latter is much higher. With increasing number of cycles, the hysteresis loop slightly migrates along the strain axis. The stress-strain responses during the first five cycles of the test are plotted in Figure 4. It is seen that the stress-strain curves are concave-upward under both uniaxial and triaxial conditions. The reason is that, during each cycle, the microcracks and microvoids within the sample were firstly compacted and then released, resulting in irreversible deformation. Furthermore, the effect of confining pressure on the concave-upward phenomenon for the cyclic loading is more obvious.

Once the majority of existing cracks have closed at the end of the initial concave part in the axial stress-strain curve, linear elastic deformation takes place. The crack initiation stress, $\sigma_{\mathrm{ci}}$, is usually defined by the onset of stable crack growth [8]. AE activities change at $\sigma_{\mathrm{ci}}$ and they gradually increase as more new cracks are initiated and the existing cracks coalesce and extend their lengths. When the applied stress is above the stress level, AE counts start to increase dramatically. Subsequently, crack propagation and growth will continue until sample failure. The failure modes of the samples subjected to monotonic and cyclic loading are compared in Figure 5. It is noticed that both the samples have longitudinally splitting cracks visible to the naked eye, but the cracks in the sample subjected to cyclic loading are much denser with a larger opening. This indicates that more energy was dissipated, which can be illustrated by the steady increase of the bounded areas of plastic hysteresis loops (Figure 4).

The shear failure with an oblique fissure can be observed in the samples from triaxial tests. The reason is that once the peak stress was experienced, the cracks concentrated near a potential shear plane. Subsequently, the crack density in this region increased drastically, starting first at one end and then expanding to the other end of the sample. As 


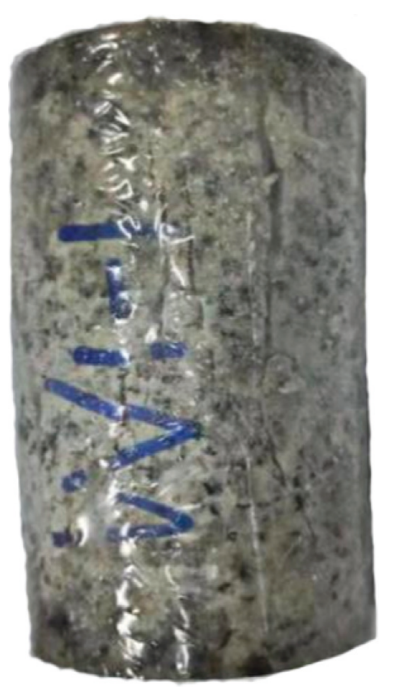

(a)

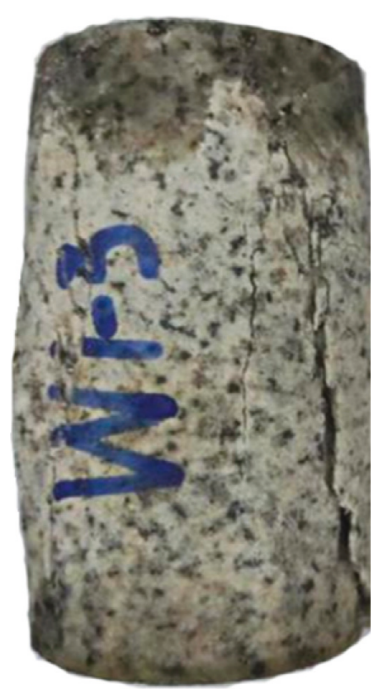

(b)

Figure 5: Comparisons of failure modes of samples under uniaxial compression. (a) Monotonic loading. (b) Cyclic loading.

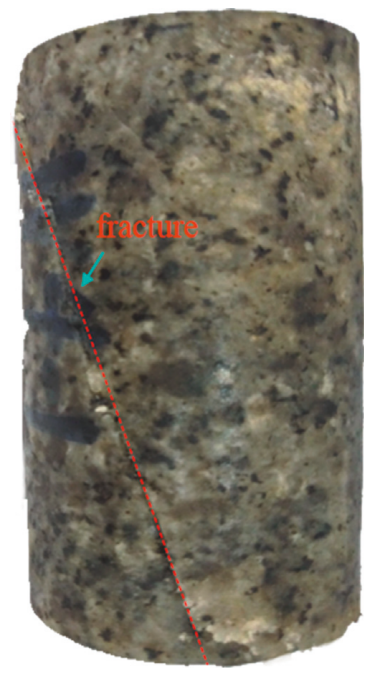

(a)

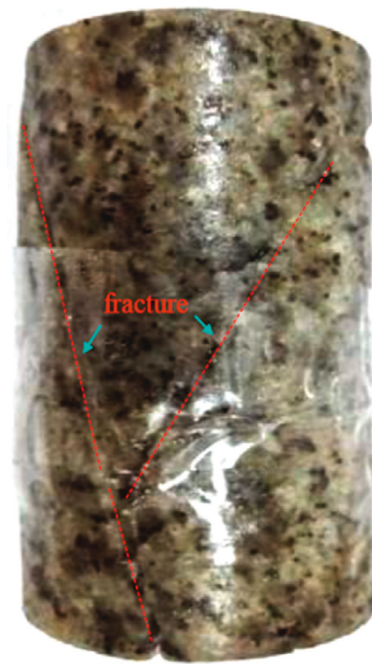

(b)

Figure 6: Comparisons of failure modes of samples under triaxial compression. (a) Monotonic loading. (b) Cyclic loading.

a consequence, a macroscopic shear fracture was formed under monotonic triaxial loading (Figure 6(a)). However, dual shear planes appeared in the sample under cyclic triaxial loading (Figure 6(b)). It is mainly due to the continuous damage exerted by the cyclic compression. The stress at the unloading point increases successively, and the redeveloped microcracks emerged gradually. Eventually, the coalescence of the axially aligned microcracks most easily caused more than just one shear fractures.

3.2.2. Analysis of Elastic Modulus and Strength. By analyzing the stress-strain data, the elastic modulus of the samples under cyclic loading can be obtained. The variations of the elastic modulus with the cycle number under different confining pressures are shown in Figure 7. Herein, the elastic modulus is defined as the slope of the linear segment (the stress-strain curve in the elastic region). It is seen that the elastic modulus increases with the increase of cycle number at different confining pressures. This is because the microcracks are quite difficult to extend when the sample bears progressive compaction; the rock stiffness is thus improved. However, the rate of increase in elastic modulus tends to reduce. Therefore, the definition of damage parameter in terms of the elastic modulus of rock material obtained from the cyclic loading test requires further investigation $[3,19]$.

As shown in Figure 8, the peak strengths $\left(\sigma_{\mathrm{s}}\right)$ of the samples are compared between monotonic and cyclic loading under different confining pressures. The average of the uniaxial strength for the monotonic loading is larger 


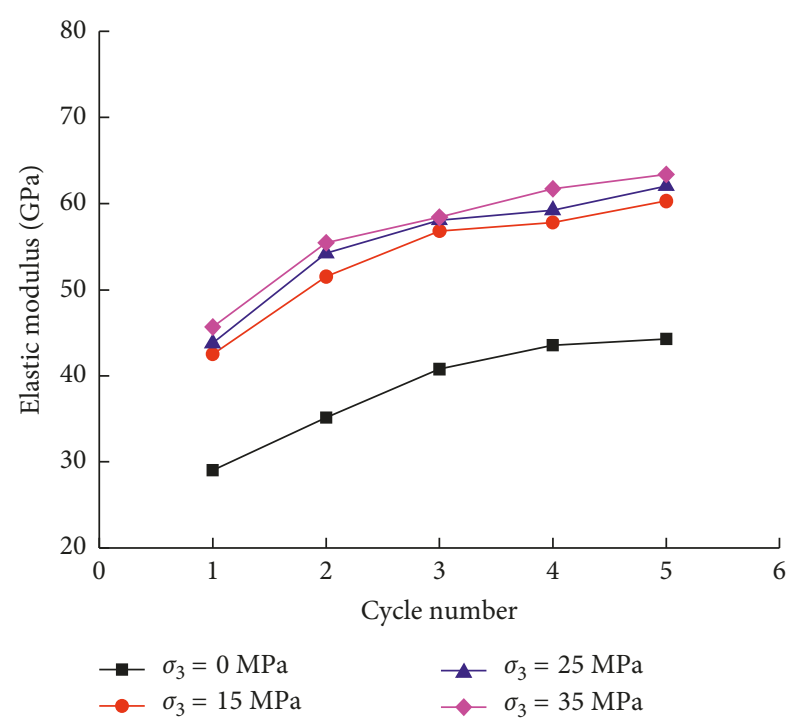

FIGURE 7: Variations of elastic modulus with cycle number under different confining pressures.

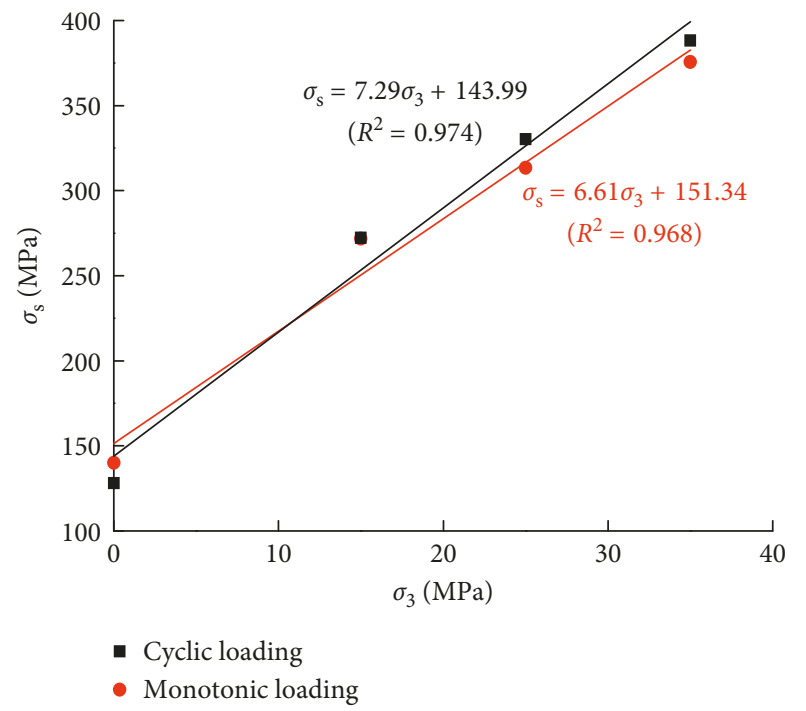

FIGURE 8: Comparison of peak strengths between monotonic and cyclic loading.

than that for the cyclic loading (i.e., 139.9 MPa versus 128.1 MPa). However, the reverse occurs under the triaxial condition, with higher average triaxial strengths for the cyclic loading at the confining pressures of $15 \mathrm{MPa}$, $25 \mathrm{MPa}$, and $35 \mathrm{MPa}$. It is also seen that the peak strength increases approximately linearly with confining pressure for both uniaxial and triaxial tests. The linear regression lines and corresponding equations are also given in Figure 8. According to the regression lines, the triaxial strength of the granite under cyclic loading is equal to that under monotonic loading at a certain confining pressure (about $10.8 \mathrm{MPa}$ here). Obviously, the cyclic triaxial strength increases with the confining pressure by a higher gradient than the monotonic one. As such, it is demonstrated that both the confining pressure and the loading

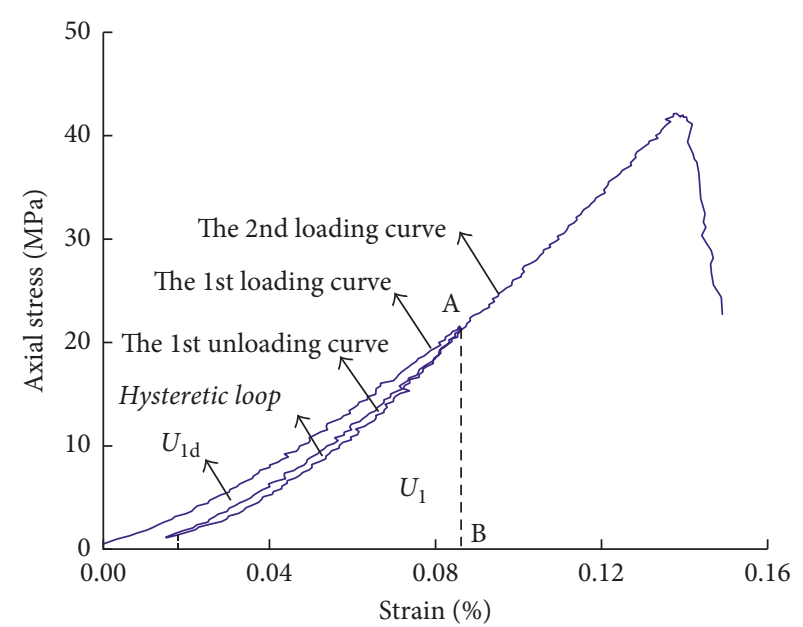

Figure 9: Schematic of energy calculation during loadingunloading cycle.

condition have considerable influence on the peak strength of the rock sample.

3.3. Characteristic of Energy Change. The deformation and failure of rock are relevant to its internal energy changes, including energy accumulation, release, and dissipation. During the compressive test, the work done by the external load on the rock sample $U$ is partly transformed into the elastic strain energy $U_{\mathrm{e}}$ that can be released and partly dissipated by the nonlinear mechanism inside the sample. In general, the dissipated energy $U_{\mathrm{d}}$ consists of plastic potential energy $U_{s}$ and damage energy $U_{\theta}$, and the plastic potential energy is just the thermal energy $[20,21]$ :

$$
U=U_{\mathrm{e}}+U_{\mathrm{s}}+U_{\theta}
$$

Assuming no heat exchange between the sample and the external, there exists $U_{\mathrm{d}}=U_{\theta}$; thus, the energy equation can be expressed as

$$
U=U_{\mathrm{e}}+U_{\theta}=U_{\mathrm{e}}+U_{\mathrm{d}} .
$$

The calculation of energy under cyclic loading is shown in Figure 9. It is seen that for the 1st loading-unloading cycle, the input energy $U_{1}$ is the area of the region OAB. The elastic strain energy $U_{\mathrm{el}}$ corresponds to the area under the unloading stress-strain curve and the strain axis, and the dissipated energy equals to the area surrounded by the first loading curve, the first unloading curve, and the strain axis; that is, $U_{\mathrm{d} 1}=U_{1}-U_{\mathrm{e} 1}$. Similarly, for the $i$ th cycle, the dissipated energy is denoted as $U_{d i}$. Because each sample was loaded to failure after five cycles, the input energy of the last cycle (6th) is considered to be the dissipated energy of the sample in this study.

It is seen from Table 1 and Figure 10 that the input energy, elastic strain energy, and dissipated energy all increase with increasing the cycle number. This is related to the particular pattern of the cyclic loading test in this study; that is, the applied cyclic stress on the sample increased with the number of cycles. Besides, the input energy, elastic 
TABLE 1: Energy and damage for the samples under different confining pressures.

\begin{tabular}{|c|c|c|c|c|c|c|}
\hline$\sigma_{3}(\mathrm{MPa})$ & $\begin{array}{l}\text { Number of } \\
\text { cycles }(n)\end{array}$ & $\begin{array}{c}\text { Upper limit } \\
\text { of stress }(\mathrm{MPa})\end{array}$ & $\begin{array}{c}\text { Total input } \\
\text { energy }\left(\mathrm{J} \cdot \mathrm{m}^{-3}\right)\end{array}$ & $\begin{array}{l}\text { Elastic strain } \\
\text { energy }\left(\mathrm{J} \cdot \mathrm{m}^{-3}\right)\end{array}$ & $\begin{array}{c}\text { Dissipated } \\
\text { energy }\left(\mathrm{J} \cdot \mathrm{m}^{-3}\right)\end{array}$ & $\begin{array}{c}\text { Damage } \\
\text { value }\end{array}$ \\
\hline \multirow{6}{*}{0} & 1 & 21.60 & 7.66 & 6.65 & 1.01 & 0.0045 \\
\hline & 2 & 42.20 & 23.98 & 20.33 & 3.65 & 0.0160 \\
\hline & 3 & 63.26 & 44.32 & 39.39 & 4.93 & 0.0208 \\
\hline & 4 & 84.32 & 73.41 & 62.03 & 11.38 & 0.0512 \\
\hline & 5 & 105.46 & 106.85 & 92.11 & 14.74 & 0.0664 \\
\hline & 6 & 133.38 & 186.40 & - & 186.40 & 0.8392 \\
\hline \multirow{6}{*}{15} & 1 & 38.81 & 17.09 & 15.07 & 2.02 & 0.0031 \\
\hline & 2 & 76.77 & 56.43 & 48.87 & 7.56 & 0.0115 \\
\hline & 3 & 115.16 & 108.09 & 96.30 & 11.79 & 0.0179 \\
\hline & 4 & 153.62 & 190.71 & 171.70 & 19.01 & 0.0289 \\
\hline & 5 & 191.79 & 285.92 & 260.67 & 25.25 & 0.0384 \\
\hline & 6 & 257.53 & 592.69 & - & 592.69 & 0.9003 \\
\hline \multirow{6}{*}{25} & 1 & 43.77 & 22.00 & 19.01 & 2.99 & 0.0030 \\
\hline & 2 & 86.46 & 66.55 & 58.09 & 8.46 & 0.0085 \\
\hline & 3 & 129.75 & 134.11 & 122.42 & 11.69 & 0.0118 \\
\hline & 4 & 173.00 & 235.10 & 216.56 & 18.54 & 0.0187 \\
\hline & 5 & 216.19 & 346.30 & 318.83 & 27.47 & 0.0277 \\
\hline & 6 & 317.06 & 923.50 & - & 923.50 & 0.9394 \\
\hline \multirow{6}{*}{35} & 1 & 51.81 & 28.66 & 24.79 & 3.87 & 0.0034 \\
\hline & 2 & 102.77 & 91.79 & 80.46 & 11.33 & 0.0101 \\
\hline & 3 & 154.19 & 189.20 & 171.72 & 17.48 & 0.0156 \\
\hline & 4 & 205.58 & 311.16 & 291.07 & 20.89 & 0.0180 \\
\hline & 5 & 256.97 & 485.73 & 445.22 & 40.51 & 0.0362 \\
\hline & 6 & 341.85 & 1024.01 & - & 1024.01 & 0.9165 \\
\hline
\end{tabular}

strain energy, and dissipated energy for the cyclic triaxial loading are obviously higher than those of the cyclic uniaxial loading. The work done by the external load increases with the increase of confining pressure. Accordingly, the input energy and elastic strain energy also increase. However, the dissipated energy does not always increase at a rate proportional to the confining pressure. For example, the corresponding curves of dissipated energy at the confining pressures of $15 \mathrm{MPa}$ and $25 \mathrm{MPa}$ almost coincide with each other.

\section{Evaluation of Rock Damage}

4.1. Damage Parameter Based on Energy Dissipation. As mentioned above, the damage defined in terms of the elastic modulus of rock is not applicable to the cyclic loadingunloading case. In addition, there exist operational difficulties in cyclic loading tests to evaluate damage using elastic wave velocity. Since the energy dissipation derives from the damage within the rock, it is feasible to define the damage parameter based on dissipated energy. For the $i$ th cycle, the damage $D(i)$ can be defined as the ratio of the current dissipated energy $U_{\mathrm{d}}(i)$ to the total dissipated energy $U_{\mathrm{d}}$ measured at sample failure under cyclic loading:

$$
D(i)=\frac{U_{\mathrm{d}}(i)}{U_{\mathrm{d}}} \text {. }
$$

The damage value equals to 0 when the sample is not loaded or in elastic stage, while it builds up to 1.0 at failure. It is seen from Figure 11 that the cumulative damage in both uniaxial and triaxial conditions increases with the increase of cyclic stress, indicating the damage continuously accumulates during the cyclic loading.

The damage due to uniaxial loading is significantly higher than that of the triaxial case. With the increase of confining pressure, the damage gradually decreases before the sample failure. This is because the extension of microcracks at the microscopic scale is restrained by the confining pressure. In the last loading cycle, the sample breaks and the dissipated energy reaches the maximum, so the corresponding damage values for different confining pressures all increase sharply.

4.2. Damage Based on Plastic Strain. During the cyclic loading, there remains a residual strain which increases from one cycle to another, implying the sample undergoes an irreversible deformation and internal damage. In terms of the plastic strain, Eberhardt et al. [14] defined the damage parameters for rocks as

$$
\begin{aligned}
& \omega_{\mathrm{ax}}=\frac{\varepsilon_{\mathrm{ax}}^{\mathrm{per}}(i)}{\sum_{i=1}^{n} \varepsilon_{\mathrm{ax}}^{\mathrm{per}}(i)}, \\
& \omega_{\text {lat }}=\frac{\varepsilon_{\mathrm{lat}}^{\mathrm{per}}(i)}{\sum_{i=1}^{n} \varepsilon_{\mathrm{lat}}^{\mathrm{per}}(i)}, \\
& \omega_{\mathrm{vol}}=\frac{\varepsilon_{\mathrm{vol}}^{\mathrm{per}}(i)}{\sum_{i=1}^{n} \varepsilon_{\mathrm{vol}}^{\mathrm{per}}(i)},
\end{aligned}
$$

where $\varepsilon_{\mathrm{ax}}^{\text {per }}(i), \varepsilon_{\text {lat }}^{\text {per }}(i)$, and $\varepsilon_{\mathrm{vol}}^{\text {per }}(i)$ are, respectively, the axial, lateral, and volumetric plastic strain; $\omega_{\text {ax }}, \omega_{\text {lat }}$, and 


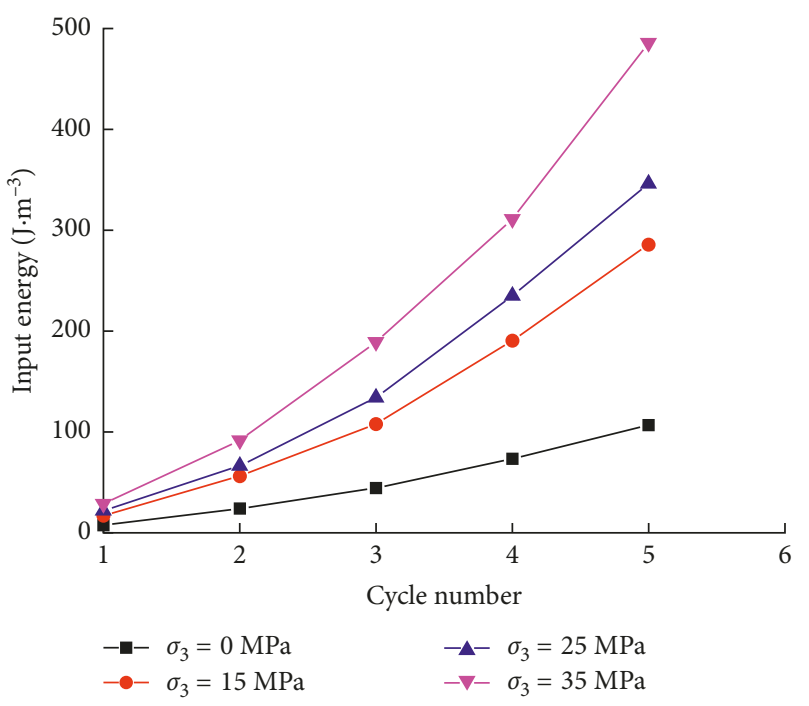

(a)

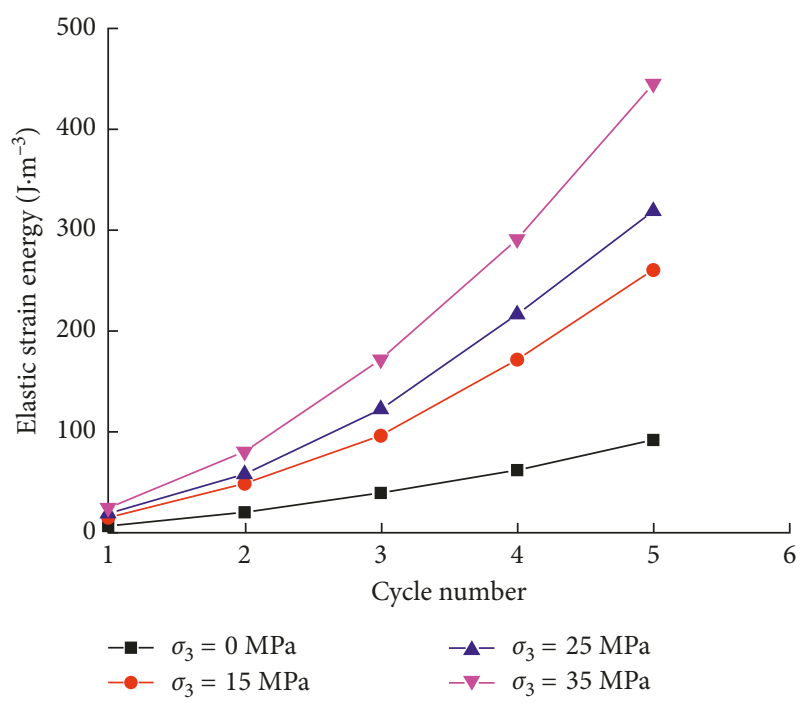

(b)

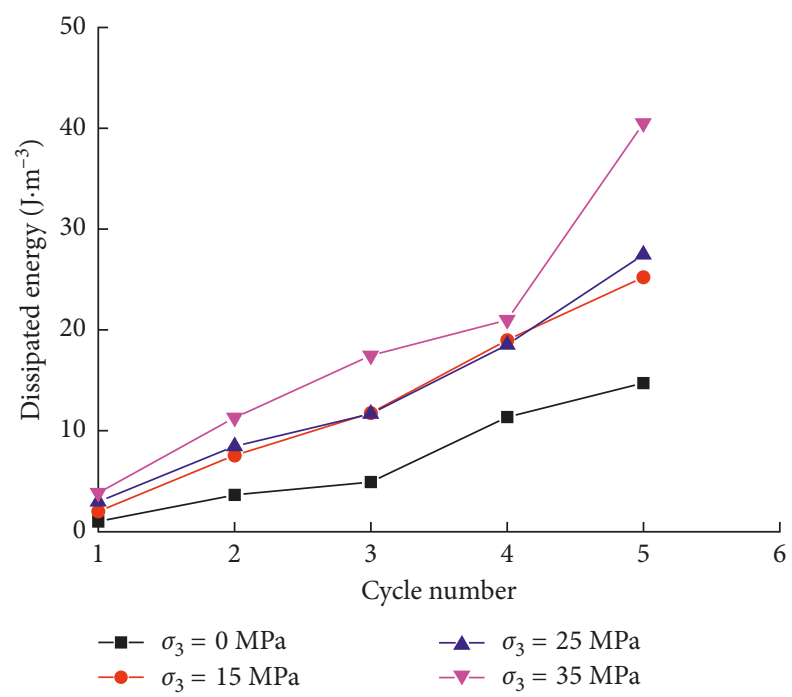

(c)

FIGURE 10: Variations of energy with cycle number under different confining pressures. (a) Input energy; (b) elastic strain energy; (c) dissipated energy.

$\omega_{\mathrm{vol}}$ are the damage parameters of the axial, lateral, and volumetric strain, respectively; and $n$ denotes the number of cycles.

Studies show that (4)-(6) can well calculate the damage of rock subjected to cyclic loading [14], whereas for the last loading cycle (i.e., cycle of sample failure), it is difficult to accurately assess the damage parameters owing to the lack of axial and lateral plastic strain. Therefore, all the damage parameters were only evaluated from the first cycle to the last but one cycle in the literature $[14,22]$. However, it is known that the cumulative damage of the rock sample actually is not equal to 1.0 before the sample failure (i.e., before the last cycle). To overcome this inadequacy, the peak strain (strain at the peak of the stress-strain curve) is approximately taken as the irreversible plastic strain for the last cycle, and thus the above damage definitions can be extended for the whole loading process.
A comparison of damage parameters is presented in Figure 12. It is seen that the obtained damage values are obviously larger if the 6th cycle is ignored.

4.3. Comparison of Damage Parameters. The damage parameters defined in terms of the energy dissipation and plastic strain under two confining pressures (i.e., 0 and $35 \mathrm{MPa}$ ) are compared in Figure 13. It can be observed that the damage parameters are very close with a marginal difference. As the cyclic stress rises, the damage increases under both the uniaxial and triaxial conditions, showing that the damage progressively accumulates during the cyclic loading process. The damage increases particularly rapidly at the last loading cycle due to sample collapse. In addition, the damage calculated by using the plastic strain definition is found to be a simple, rapid, and time-saving method. 


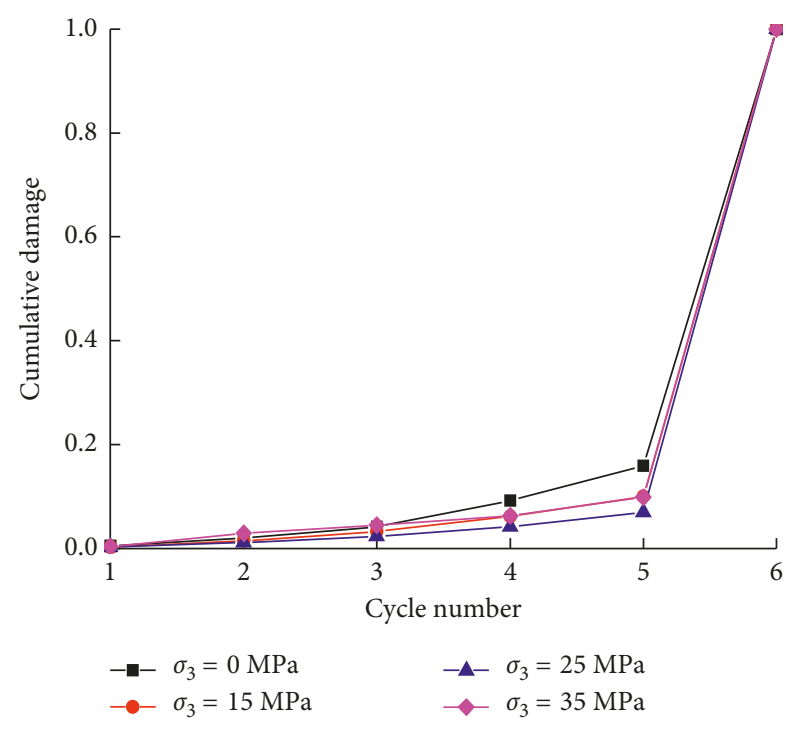

FIGURE 11: Plots of cumulative damage based on energy dissipation.

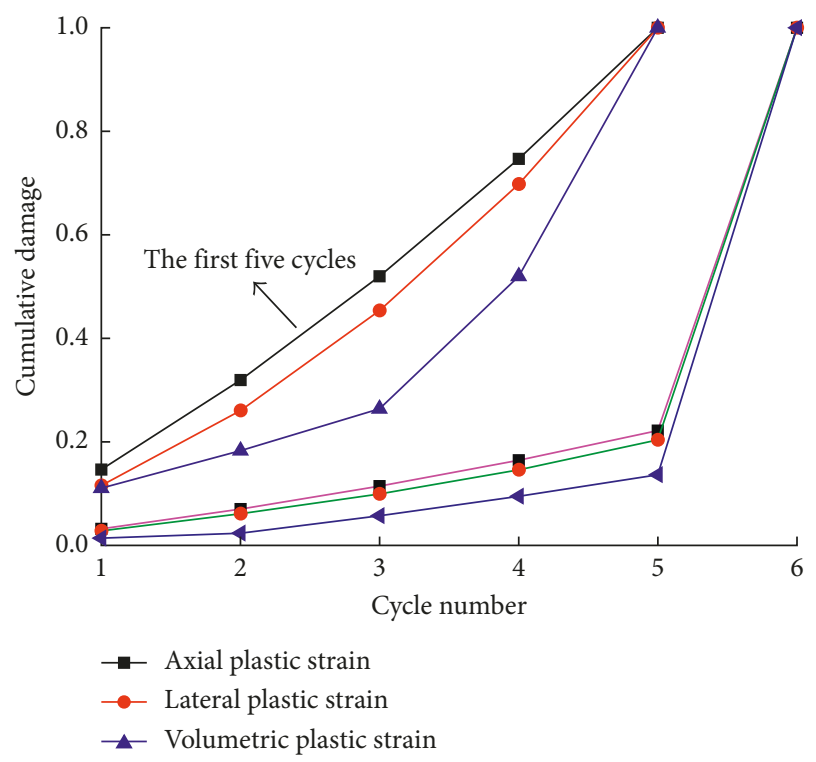

FIGURE 12: Comparison of cumulative damage based on plastic strain.

\section{Conclusions}

In this study, cyclic uniaxial and triaxial tests have been carried out on Huashan granite. Based on the experimental results, the following conclusions can be drawn:

(1) The number of AE activities is higher for the granite samples under cyclic triaxial loading compared to that under cyclic uniaxial loading. The curve of cumulative $\mathrm{AE}$ count in the uniaxial test resembles ascendant steps, whereas that of the triaxial test is almost linear. The granite has a memory function under cyclic loading.

(2) The stress-strain curves of the granite samples under cyclic axial compression are concave-up, but this phenomenon is mild for the cyclic triaxial condition. Within the selected confining pressures, the elastic

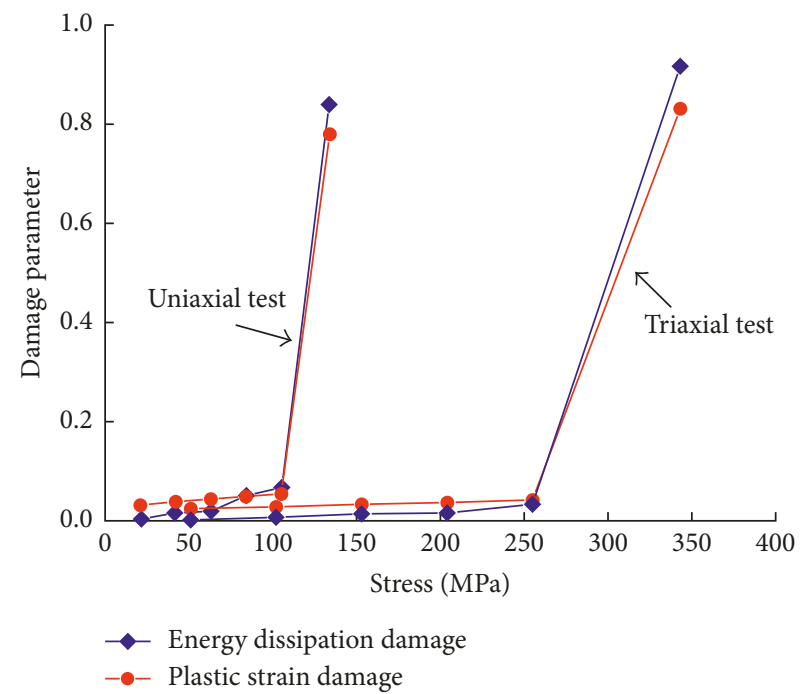

Figure 13: Comparison of two damage parameters under cyclic loading.

modulus of the rock sample firstly increases and then levels off as the cycle number rises.

(3) Both the energy dissipation-based damage and the plastic strain-based damage can avoid the deficiencies in the traditional definitions of damage. An extension has been proposed for the plastic strainbased damage by selecting the peak strain as the irreversible plastic strain for the damage evaluation of the last loading cycle. This extension improves the applicability of the plastic strain-based damage, and the calculated results agree well with the damage defined in terms of energy dissipation.

\section{Conflicts of Interest}

The authors declare that they have no conflicts of interest.

\section{Acknowledgments}

This study was financially supported by the National Natural Science Foundation of China (Grant nos. 51579062, 51379147), which is gratefully appreciated.

\section{References}

[1] B. H. G. Brady and E. T. Brown, Rock Mechanics for Underground Mining, Kluwer Academic Publishers, Dordrecht, Netherlands, 3rd edition, 2006.

[2] H. P. Xie, J. Pei, J. Zuo, and R. Zhang, "Investigation of mechanical properties of fractured marbles by uniaxial compression tests," Journal of Rock Mechanics and Geotechnical Engineering, vol. 3, no. 4, pp. 302-313, 2011.

[3] H. P. Song, H. Zhang, Y. L. Kang, G. Y. Huang, D. H. Fu, and C.Y. Qu, "Damage evolution study of sandstone by cyclic uniaxial test and digital image correlation," Tectonophysics, vol. 608, no. 6, pp. 1343-1348, 2013.

[4] J. Liu, H. Xie, Z. Hou, C. Yang, and L. Chen, "Damage evolution of rock salt under cyclic loading in unixial tests," Acta Geotechnica, vol. 9, no. 1, pp. 153-160, 2014. 
[5] W. Chen, H. Konietzky, X. Tan, and T. Frühwirt, "Pre-failure damage analysis for brittle rocks under triaxial compression," Computers and Geotechnics, vol. 74, pp. 45-55, 2016.

[6] Y. Zong, L. Han, J. Wei, and S. Wen, "Mechanical and damage evolution properties of sandstone under triaxial compression," International Journal of Mining Science and Technology, vol. 26, no. 4, pp. 601-607, 2016.

[7] Z. Wang, S. Li, L. Qiao, and Q. Zhang, "Finite element analysis of the hydro-mechanical behavior of an underground crude oil storage facility in granite subject to cyclic loading during operation," International Journal of Rock Mechanics and Mining Sciences, vol. 73, pp. 70-81, 2015.

[8] X. G. Zhao, M. Cai, J. Wang, and L.K. Ma, "Damage stress and acoustic emission characteristics of the beishan granite," International Journal of Rock Mechanics and Mining Sciences, vol. 64, no. 12, pp. 258-269, 2013.

[9] Y. H. Li, J. P. Liu, X. D. Zhao, and Y. J. Yang, "Experimental studies of the change of spatial correlation length of acoustic emission events during rock fracture process," International Journal of Rock Mechanics and Mining Sciences, vol. 47, no. 8, pp. 1254-1262, 2010.

[10] M. C. He, J. L. Miao, and J. L. Feng, "Rock burst process of limestone and its acoustic emission characteristics under truetriaxial unloading conditions," International Journal of Rock Mechanics and Mining Sciences, vol. 47, no. 2, pp. 286-298, 2010.

[11] E. Aker, D. Kühn, V. Vavryčuk, M. Soldal, and V. Oye, "Experimental investigation of acoustic emissions and their moment tensors in rock during failure," International Journal of Rock Mechanics and Mining Sciences, vol. 70, no. 3, pp. 286-295, 2014.

[12] S. Dhar, P. M. Dixit, and R. Sethuraman, "A continuum damage mechanics model for ductile fracture," International Journal of Pressure Vessels and Piping, vol. 77, no. 6, pp. 335-344, 2000.

[13] J. F. Shao and R. Khazraei, "Wellbore stability analysis in brittle rocks with continuous damage model," Rock Mechanics in Petroleum Engineering, vol. 58, no. 8, pp. 2994-3000, 1994.
[14] E. Eberhardt, D. Stead, and B. Stimpson, "Quantifying progressive pre-peak brittle fracture damage in rock during uniaxial compression," International Journal of Rock Mechanics and Mining Sciences, vol. 36, no. 3, pp. 361-380, 1999.

[15] H. P. Xie, L. Li, R. Peng, and Y. Ju, "Energy analysis and criteria for structural failure of rocks," Journal of Rock Mechanics and Geotechnical Engineering, vol. 1, no. 1, pp. 11-20, 2009.

[16] X. S. Liu, J. G. Ning, Y. L. Tan, and Q. H. Gu, "Damage constitutive model based on energy dissipation for intact rock subjected to cyclic loading," International Journal of Rock Mechanics and Mining Sciences, vol. 85, pp. 27-32, 2016.

[17] C. Khazaei, J. Hazzard, and R. Chalaturnyk, "Damage quantification of intact rocks using acoustic emission energies recorded during uniaxial compression test and discrete element modeling," Computers and Geotechnics, vol. 67, pp. 94-102, 2015.

[18] J. A. Franklin, "Suggested methods for determining the strength of rock materials in triaxial compression: revised version," International Journal of Rock Mechanics and Mining Science and Geomechanics Abstracts, vol. 20, no. 6, pp. 285290, 1983.

[19] R. D. Peng, Y. Ju, F. Gao, H. P. Xie, and P. Wang, "Energy analysis on damage of coal under cyclical triaxial loading and unloading conditions," Journal of China Coal Society, vol. 39, no. 2, pp. 245-252, 2014.

[20] D. Song, E. Wang, and J. Liu, "Relationship between EMR and dissipated energy of coal rock mass during cyclic loading process," Safety Science, vol. 50, no. 4, pp. 751-760, 2012.

[21] X. G. Chen and Q. Y. Zhan, "Research on the energy dissipation and release in the process of rock shear failure," Journal of Mining and Safety Engineering, vol. 27, no. 2, pp. 179-184, 2010.

[22] J. Zhou, X. Yang, W. Fu et al., "Experimental test and fracture damage mechanical characteristics of brittle rock under uniaxial cyclic loading and unloading conditions," Chinese Journal of Rock Mechanics and Engineering, vol. 29, no. 6, pp. 1172-1183, 2010. 


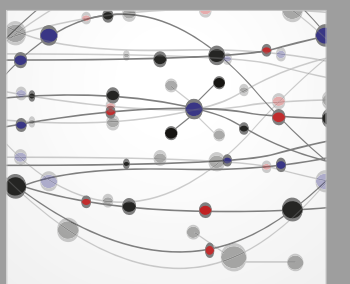

The Scientific World Journal
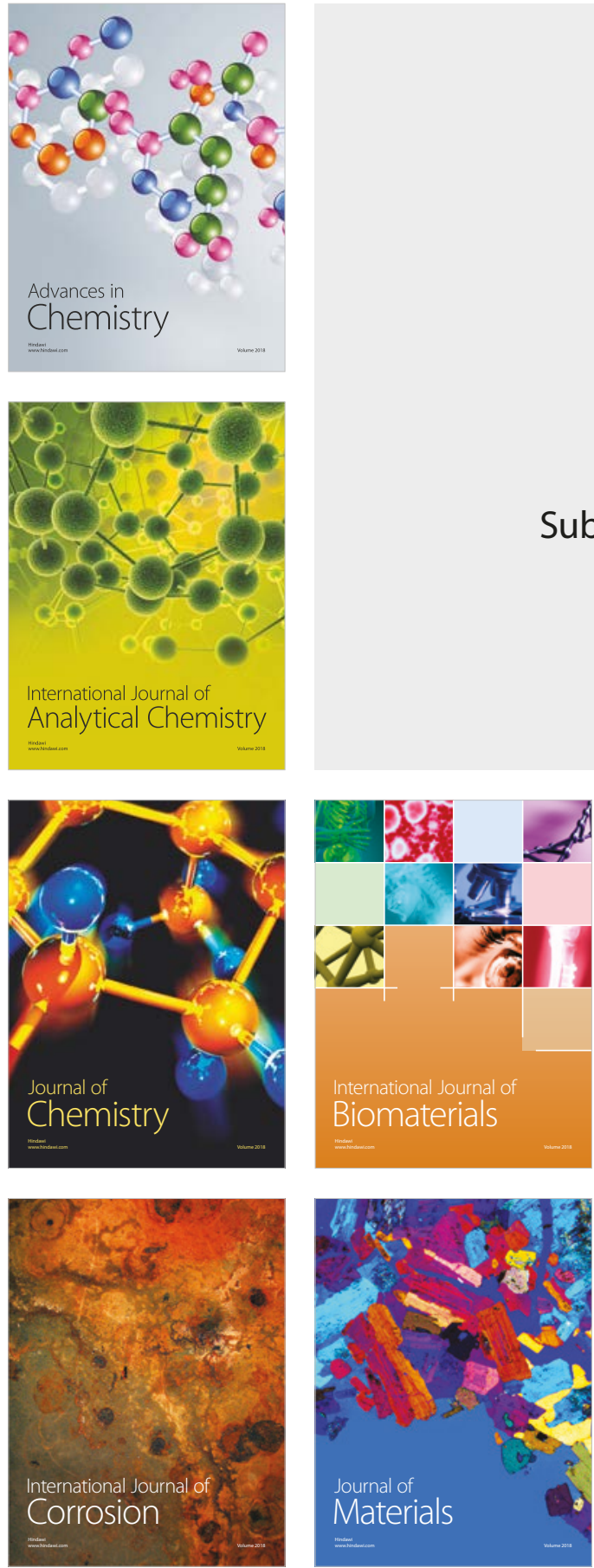

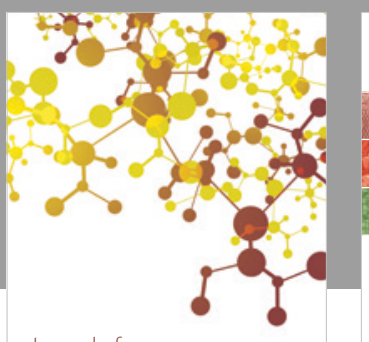

Journal of

Applied Chemistry
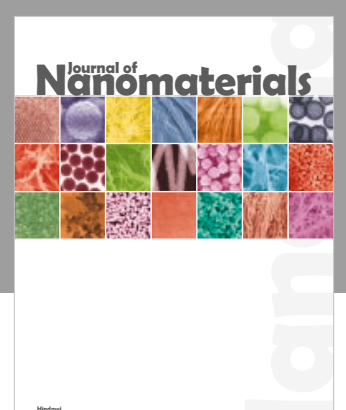

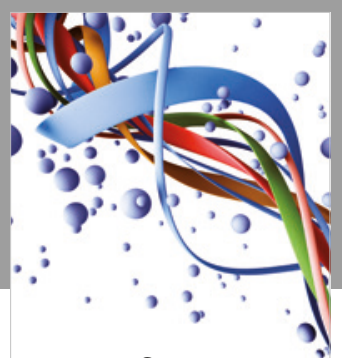

Scientifica

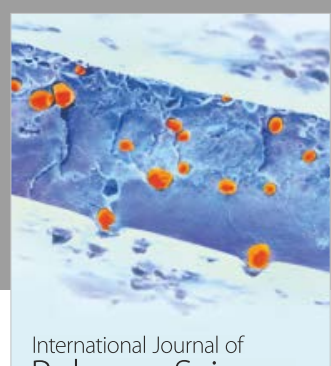

Polymer Science

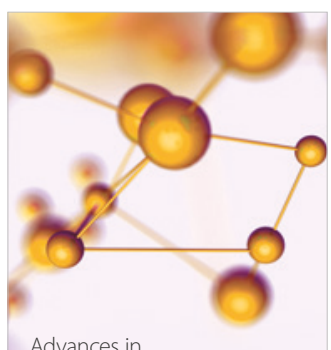

Physical Chemistry
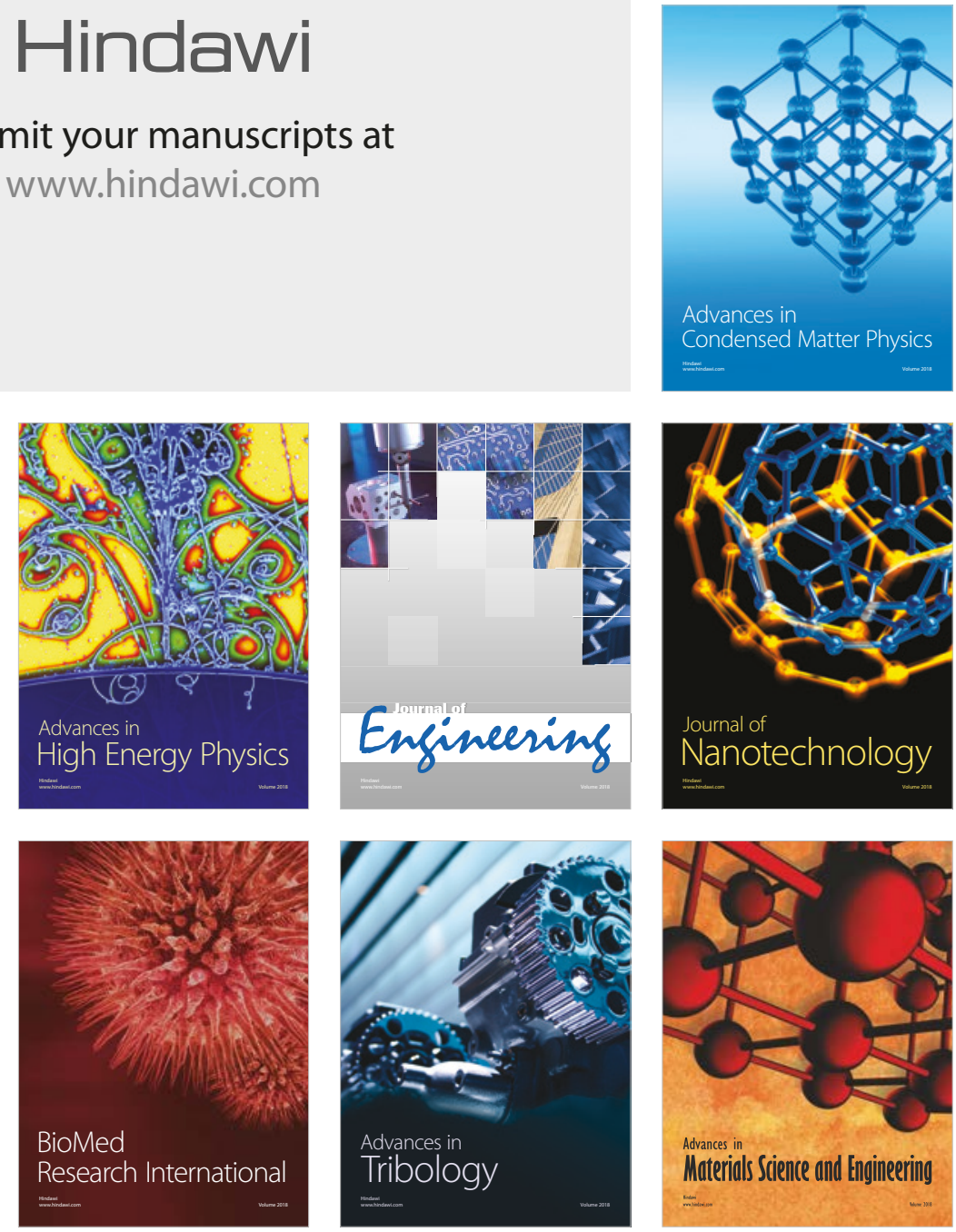